Article

\title{
Over Time and Beyond Disney-Visualizing Princesses through a Comparative Study in India, Fiji, and Sweden
}

\author{
Charu Uppal \\ Department of Geography, Media and Communication, Karlstad University, 65188 Karlstad, Sweden; \\ charu.uppal@kau.se
}

Received: 24 December 2018; Accepted: 23 March 2019; Published: 31 March 2019

check for updates

\begin{abstract}
Disney animated princesses are broadcasted around the world through Disney Channel and its global affiliates as well as through numerous other networks that purchase distribution rights. In an attempt to provide diversity in the last 25 years, Disney has featured nonwestern princesses such as those in Aladdin (1992), Pocahontas (1995), Mulan (1998), and Moana (2016). This study examines how princesses in animated Disney movies are perceived and understood by girls (8-15 years) in three different countries, over two time-periods with a gap of nearly a decade (2009 and 2018). The primary research question, considering Disney's global reach, is how race, culture, and presence of a royal family interact with transnational access to the same media content in the perception of the princess concept and about being a girl. The selected countries provide an opportunity to explore differences in perception of Disney princesses between girls raised in countries with and without a royal family, and between girls in nonwestern and western countries. Differences in the perception are attributed to local and national cultures that allow a different lens to view the same content. A mixed method combining interviews, focus groups, and participant-generated images was used to gather data in India, Fiji, and Sweden. Results indicate Disney princesses, with their ubiquitous presence in various formats, e.g., media content, costumes and school stationery, have created a uniform idea of beauty across countries. Princesses in Disney were perceived by participants as being Caucasian and American, regardless of the race or country they represented. Girls in India and Fiji did not identify with Jasmine or Mulan, whom they considered 'American', whereas girls in Sweden considered Jasmine and Mulan as princesses of nonwestern origin. Girls in India and Fiji did not think they could be princesses because of their skin color, and did not want to lead a life 'restricted with responsibilities', but girls in Sweden considered the same question from the place of a choice, i.e., they preferred not to lead a 'boring' and regulated life like that of a princess. Participants from Fiji, with the least access to domestic programming that showed girls of their same Fijian origin, were least likely to consider themselves capable of being a princess.
\end{abstract}

Keywords: Disney; girls; beauty; transnational media; princess

\section{Introduction}

The 'Disney Universe' ${ }^{1}$ has captured audiences and consumers around the world for nearly a century. On its international website ${ }^{2}$, the company that appeals mostly to children and young adults, lists nine online destinations, seven of which are regions or continents-Asia, Africa, Australia, Europe,

1 As used in J. Wasko, 2001.

2 http://www.disneyinternational.com. 
North America, Latin America, and Middle East, and two of which are countries with large populations, India and Russia. The website lists India, a country of 1.3 billion people, with a growing market that consumes much media in English, as a separate market from Asia ${ }^{3}$. Each tab has a drop-down menu that takes the viewer to country and language-specific content. Each region is further divided into many subregions and countries. In essence, Disney is everywhere. If not in theatres, then it can be found on electronic screens that are omnipresent, or as logos and images, posters and book covers, theme designs for birthday cakes, and even professionally painted onto the walls of young children's rooms ${ }^{4}$ (Figure 1).

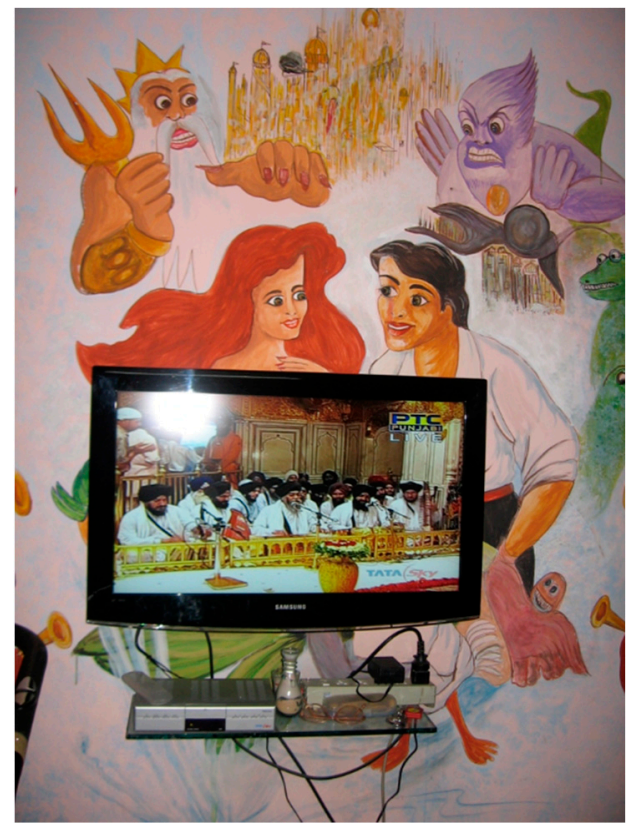

Figure 1. Scenes from Little Mermaid on a wall in a house in India.

This study illustrates how Disney's global presence mainstreams views on being a girl. Disney's global presence has been critiqued both for perpetuating stereotypical images (England et al. 2011) and its potential impact on cultures, especially in countries lacking domestic programming that relies on western media content (Forman-Brunell and Hains 2014). Ubiquity of American media including Disney, and the absence of media rooted in native cultures can hamper young girls' identification with and taking pride in their own culture. Domestic audio-visual programming focusing on culturally relevant stories and folklore can potentially empower young girls to counter Disney's transnational but monocultural narrative (Nastasia and Uppal 2014). Countries that do not have a thriving domestic media industry present no competition to transnational media content. Not surprisingly, Fiji, a country which lacks domestic industry, ${ }^{5}$ does not attract Disney's interest, and is missing from its international website, possibly because it is a small market and Disney is aware that lack of competition in the country ensures viewership.

Sweden, India, and Fiji, the locales of research for this study, provide a complex intertwining of variables which allow examining the role of Disney princesses on young girls' perceptions about being a girl. The three countries, as described in detail in the following sections, vary in culture, ethnicity, and use of transnational media.

\footnotetext{
http://www.disneyinternational.com/\#panel1i, accessed September 2018.

The researcher had seen one such wall-painting in India.

While Bollywood, the Hindi film industry of India, is prominent in Fiji, it is consumed mainly by Indo-Fijians who constitute less than $40 \%$ of the population, due to language constraints.
} 
This comparative study examines data gathered through a participatory study on girls between 8 and 15 years of age in three different countries over two time periods nearly a decade apart-India and Fiji, in 2009, and Sweden in 2018. All three countries are democracies ${ }^{6}$ with considerable differences, that function as variables. Sweden, a constitutional monarchy, has a modest media industry and leads in the use of internet and social media among the three countries. India, the largest democracy, has possibly the largest media industry, but without the same international appeal or reach as Disney. Fiji consumes mostly western media, with the exception of Indian media products mostly consumed by people of Indian diaspora. While India, a democracy since 1947, only opened its audiences to foreign media since economic liberalization in the 1990s, Sweden is a much older democracy that has a royal family and real-life princesses. Fiji, the smallest in population among the three, also has the least robust domestic media industry, where television was introduced as late as 1991. In addition, Sweden is largely a Caucasian country, whereas India has ethnic diversity that is known more by lingual and cultural rather than racial differences. Fiji, a multicultural country, constitutes several ethnicities of which Fijian and Indo-Fijans form over eighty percent.

By comparing data from two time periods and on three different continents, the study critically analyzes the intricate link between location/geography, exposure to Disney animated princesses, visualization of the concept of princess, and whether domestic cultures are articulated despite Disney's popularity and allow culturally representative images of princesses, a concept which is an important component of playtime for girls (Wohlwend 2009; Pollen 2011).

In creating brands and homogenizing appearances, Disney's depiction, bound by western ways of looking at the world, molds even the princesses of Chinese, Pacific, and Middle Eastern descent such that they are perceived to be western. For example, though Disney's Pochahantas and Mulan are considered atypical princesses that challenge stereotypical images in Disney, research suggests that nonwestern girls consider them western/American and do not identify with them (Lemish 2010; Nastasia and Uppal 2014, 2010). In comparison to Disney, a historically girl-oriented channel, Nickelodeon, is considered more balanced in providing programming for both girls and boys (Lemish 2010) with regard to screen time. ${ }^{7}$

Beyond catering to one gender over the other, scholars have argued that Disney's programming creates misconceptions of the real world. Schickel (1997) argued that Disney animated films in creating a world with dichotomous characters that can be divided into villains and heroes, promoted the values of upper class, and supported commercial enterprises. Scholars have likened the magical realm created in Disney movies to that of capitalism where labor and work remain hidden, and most do not seem to work for the 'necessities of life' (Dorfman and Mattelart 1975, p. 68), nor do they reflect realities of life (Wasko 2001). Furthermore, scholars have demonstrated a hierarchy in Disney, where masculinity and whiteness are presented as positive, strong, and central to the plots, and female characters are shown to be frail and shy (Lawrence 1986). Western values of individualism are upheld, as opposed to community and duty to the extent that nonwestern stories are altered to suit Disney's narrative (Limbach 2013). For example, in the ballad of Hua Mulan, the basis for Disney version of the story, the protagonist cross-dresses as a man with the help of her parents, but in the Disney rendition, she does so by breaking 'away from her family to find her identity' (p. 115); and while in the actual story, Mulan spends twelve years in training and fights several battles, in the movie, her screen time dressed as a man is comparatively short (Limbach 2013). Disney, wary of blurring the lines between male and female, not only limits Mulan's screen time dressed as a man, which could counteract concepts of gender as binary, but also portrays being a man as a more 'active' process in comparison to being a woman/girl (Limbach 2013, p. 119).

\footnotetext{
Although Fiji had its fourth coup in 2006, since then there have been two elections.

Although scholars have argued that even on Nickoldean shows featuring 'girls' often struggle between 'strong' vs. 'feminine' portrayal of girls (Hains 2007).
} 
While Disney's universe is inhabited by diverse characters, Disney princesses have created a world that has captured girls' imagination around the world and now command their own website as a Disney brand ${ }^{8}$. Now worth over four billion USD, the brand was created in 2000 , by the then- CEO after observing young girls dressed as princesses in homemade costumes when attending shows such as Disney on Ice (Pollen 2011). Stories of Disney princesses are woven into young girls' play and fantasy world, often supplemented with costumes referring to Disney princesses (Wohlwend 2009; Pollen 2011; Garabedian 2015). As Forman-Brunell and Hains (2014) state, "Princesses are everywhere there are girls" (p. xi), and Disney's multiple ventures supplement the princess culture with costumes and accessories to manifest a fantasy world. Childhood, suggest some scholars, is threatened by the 'childhood culture industry' (Pollen 2011), which now mass manufactures clothing, toys, and accessories connected with fantasy play, limiting options available for imaginative and performative play. While young girls dressing up is a practice as old as fairy tales, mass production and growth of the children's clothing market that manufactures fantasy costumes have driven demand for princess costumes. This trend of using costumes in play is also accompanied by a 'pinkification' of outfits and objects aimed at young girls (Pollen 2011). Pollen (2011) argues that though associating pink with girls is fairly recent, the trend towards 'pinkification' is so prominent that it is even considered to be an indicator of a biological imperative. In a survey conducted to understand the link between available fantasy (dressing-up) outfits for girls and the issue of agency in performative play and creation/performance of femininity, Pollen (2011) establishes that limits on playing/performing being a girl are woven into the fabrics, colors, and the designs of the costumes available to the girls, which are often purchased and promoted by parents themselves. Whether or not young girls perform femininity normatively (as outlined by Judith Butler), girls practicing agency during playtime can challenge stereotypical concepts of girlhood (Pollen 2011) and is considered 'appealing and confining' at the same time (Wohlwend 2009, p. 80). However, the motives for wearing pink or glittery outfits is an indication that the girls associate it with being pretty and with popular characters whom they want to emulate (Pollen 2011). Although childhood theorists stress that a child uses his/her agency just as much as an adult and is not always passively imitative (James et al. 1998; Clarke 2007; Wohlwend 2009), Pollen (2011) through her study demonstrates that designs, colors, and fabrics used for fantasy costumes limit that agency. For example, in the sample used to study various outfits used for play by young girls, 14 of 52 outfits were based on princess characters, where 12 out of 52 costumes were Disney characters (Pollen 2011). Disney's popularity has standardized the appearance of Disney princesses, unlike original story books with more imaginative and varied princess content. Merchandise then facilitates the emulation of Disney images e.g., wearing the appropriate outfit along with tiaras or wands, etc. (Pollen 2011). In fact, Disney's popularity is so prevalent that a study found no correlation between screen time spent watching Disney princess films and owning Disney Princesses products, implying that ownership of princesses merchandise was not dependent on exposure to Disney films (Golden and Jacoby 2018).

\subsection{Standardization of the Princess Concept}

The idea of royalty is embedded in the human psyche. 'Once there was a King' as several fables, fairy tales and historic stories begin in many cultures, usually evokes images of riches and luxury, even as it narrates trials and tribulations of a royal family. Addressing children as a prince or princess in most cultures is a form of endearment and a way of showing affection, although it can also imply someone who is pampered. Though the concept is universal, an authentic presentation of royalty must vary with culture, e.g., a crown, seen frequently in Disney movies featuring princesses, is not a universal marker of royalty. Similarly, long gowns, as featured in Disney, do not represent royal attire in many cultures. Famous princess tales such as Snow White and Cinderella, despite retaining plot and character names, were not uniformly drawn in picture books, which allowed for variation in the

8 https://princess.disney.com. 
visualization of these princesses. Disney's portrayal of princesses has standardized their skin color, behavior, and appearance. Other than shaping the characterization of princesses, usually depicted as young girls with long hair, Disney's uniform presentation of princesses restricts a child's imagination and behavior. Scholars argue that Disney princesses in movies such as Frozen (Elsa), despite being acclaimed as a norm-breaker for being independent (Garabedian 2015) have not learnt the value of interconnectedness of human relationships (Stehn 2018). Elsa, while embracing her authentic self, does so at the expense of personal relationships, which can be equally detrimental as forgoing self for relationships (Stehn 2018). Princess stories and fairytales are also usually connected to being Caucasian since historically 'power and privilege' are linked to being white (Dundes and Streiff 2016). Since white princesses fare better and are more successful in Disney princesses' movies than princesses of color (Dundes and Streiff 2016) young audiences associate princesses with being white. Young girls often translate what they see on screen into their playtime by enacting the scenes with the figurines sold by Disney (Wohlwend 2009; Garabedian 2015) and therefore, the appearance and behavior of Disney princesses are a significant influence on young girls.

\subsection{Sweden, Royal Family, Princesses, Media, and Disney}

Sweden, the largest among the Nordic countries, and the third largest country in Western Europe, combines a constitutional monarchy and a parliamentary form of government, although since 1975, the royal family only serves a ceremonial role and has no executive powers (Rehmann 2010; Åse 2013; Jönsson and Lundell 2009). Although until recently, the queen was recognized for her beauty and her role of providing a male heir, since 1980, the imperative of a male heir has been removed and made gender neutral, implying that it is the first born and not the first male who is the heir to the throne (Åse 2013).

Often ranked quite high in media freedom, until the mid-1980s, Swedish TV and radio were a government monopoly with strict policies against commercialization. The policies that protected Swedish airwaves from an onslaught of foreign programming have gradually been relaxed and currently the majority of content on television, including the public television, is imported. Just as with any other country, despite reservations, the majority of programming on Swedish screens, other than public broadcasting, is American. Sweden's national Donaldist society, simply called the 'Duck' (Wasko 2001), has incorporated Disney into mainstream entertainment for decades; for example, Kalle Anke (Donald Duck) is staple viewing for families on Christmas eve.

Sweden, a country that prides keeping its traditions alive, often celebrates the royal family by covering it in their media. Some scholars argue that royal families, including that of Sweden, function like a 'corporate heritage brand' (Balmer 2011) where consumers, i.e., commoners, are linked to observances that connect them to a sense of continuity and a collective past (Otnes and Maclaran 2015). Media plays an increasingly significant role in how royal weddings reach the public and maintain the myth of centrality of royal family in the lives of Swedes (Widestedt 2009). How royal families are mediated also impacts the way gender, nation, and family life are defined in the country (Åse 2013). In the last decade, Sweden has witnessed three royal weddings, all of which were highly anticipated and nationally televised (Åse 2013). However, a significant change from royal weddings of previous generations is that all the three royals-two princesses and one prince-married commoners, as has also happened in some Disney films. One of the variables explored in the study is influence of exposure to a real-life royal family in perceiving the princess concept. Would growing up in a country with a royal family bring a more realistic understanding of princesses and their lives? 


\subsection{India, Fiji, Royal Families, and Disney}

Though historically both India and Fiji ${ }^{9}$ have had princesses, or similar entities, both countries have chosen to be democracies with multiparty systems, thereby passing the role for playing princesses to celebrities. Although both India and Fiji have in the past had royal families, the tradition has been discontinued, as India became independent and Fiji ceded power to the British. Any mention of royalty or monarchy therefore happens in folktales, history, and textbooks. Disney princesses, however, have a strong presence in both the countries, where movies are released regularly, and images of Disney princesses are found in objects of everyday use for young girls such as stationery and notebooks. While India has a thriving domestic media industry, Fiji is mostly dependent on transnational media, which often originates in nonwestern countries and primarily comes from the US. However, the Indian media industry has taken a turn towards westernization as well as seen a proliferation of domestic programming in the 1980s, while Indian television has also featured several series with princesses and royalty. Disney India Limited began as a joint venture with Modi enterprises in 1993 and a decade later became an independent channel broadcasting in three Indian languages, as well as English. Relaxed rules for media and broadcasting since the liberalization of the Indian economy made it possible for Disney movies to be released at the same time as in the United States, which earlier were either never released on screens in India ${ }^{10}$ or screened years after their original release. A content analysis conducted in 2007 based on 102 hours of recorded programming established that $84 \%$ of India's children programming was imported and only 16\% was local/domestic (Götz and Lemish 2012). By 2009, when the data were collected in India and Fiji, Disney movies featuring princesses and royalty, such as Aladdin, Little Mermaid, Pocahontas, and Mulan, had been released. When the study was conducted in 2009, both Indian and Fijian children had been exposed to Disney princesses for several years.

\section{Media Use Among Children and Youth}

Any study conducted today with regard to potential influence of media viewing must also consider the many ways the same content can be accessed. With the increased access to media, and ubiquity of mobile media, even in remote corners of the world, Disney's reach has increased multifold in the last decade. Since social media's affordances, i.e., forwarding, customizing media messages, and instant interaction, encourage increased screen time, parents and teens alike are concerned about their screen time and have taken measures to reduce it (Jiang 2018).

Scholars have long commented that the use of technology among young girls has become so common that it is central to expression of their identities (Turkle 2011). Even though by the early 2000s, young girls in urban India were already using the Internet to explore the world (Verma and Sharma 2003), smart phones were not yet prevalent. Participants in India and Fiji shared that they watched Disney movies either on a playback system or television.

Sweden, a country of nearly ten million, has over ninety-five percent penetration of smart phones in the 16-24 age range (Statistics Sweden 2018). Furthermore, in Sweden, where access to media is almost universal, as opposed to India and Fiji, there is little or no difference in the amount spent on various media platforms (International Data on Youth and Media 2017). A youth and media survey suggests that for ages between 13 and 29, smart phones are the most common mode of accessing media, followed by personal computers and television (International Data on Youth and Media 2017). Data suggest that although the frequency of using smart phones increased with age between 8 and 15 years, until 2014, neither smart phones nor tablets were used every day and stationary TV was more

9 Fiji has a history of coups, having gone through four coups as of 2006. However, in September of 2014, Fiji held a democratic election, which was deemed fair by international observers. Although the data in Fiji were gathered in 2009, it is important to note that the coup had no impact on reception and distribution of entertainment media.

10 Pirated versions only in English were usually available. 
prevalent than WebTV (International Data on Youth and Media 2017), making this study significant in providing information on viewing habits and preferences of young girls. While animation remained the most watched programs worldwide, in Sweden by 2014, factual entertainment was preferred over animation and live TV was the most popular among children and youth (br.online.de).

The Internet, iPads, and laptops were well in use in 2009 when smart phones had not yet penetrated the market in both India and Fiji; therefore, movie viewing was restricted to VCRs, DVD, and television.

\section{Main Research Question and Rationale}

Considering Disney's global reach, the overarching research question for this study, is 'How do race, culture, and presence of a royal family interact with transnational access to the same media content (Disney Princesses) to influence the perception of being a girl?' The selected countries provide an opportunity to explore if there is a difference in perception of Disney princesses between girls raised in a country with and without a royal family, and between girls in nonwestern and western countries. Differences in the perception are attributed to local and national cultures that allow a different lens to view the same content. This paper compares the data collected in 2018 in Sweden with that from India and Fiji in 2009 to understand the shifts that have occurred in the way young girls perceive and consume princesses in animated Disney movies.

The rationale for comparison of data that is nearly a decade apart and in countries in with different cultures can be understood first by the global presence of Disney and its impact, as explained in the previous section, and by the use of a visual method in the study, i.e., drawing pictures of princesses, as explained in detail in the following section. By comparing research done in two time periods and on three different continents, the study critically analyzes the intricate links between location/geography, exposure to Disney animated princesses, and their perception. Culture, presence/absence of domestic media industry, presence/absence of a royal family are considered variables that may influence perception of Disney princesses. Analyzing data across time, the study attempts to understand the shifts that have occurred in the way young girls understand and consume princesses in animated Disney movies.

A secondary purpose of the study was to gather information on the viewing practices and way of accessing Disney princesses by young girls in 2018. Data from Fiji and India were collected at the cusp of the mobile media revolution, especially smart phones, so extra questions about media viewing were added for data collected in 2018.

\section{Methodology: Mixed Method, Intersecting Factors, and Research Questions}

\subsection{Mixed Method}

Data were gathered by combining three methodologies that complemented each other and compensate for the difference between cultures and ability to express. All the participants were asked to draw their version of a princess, followed by individual interviews and focus group discussions. This study, which compares data from 2009 to data gathered in 2018, conducts an in-depth analysis of drawings, and adds Sweden, as opposed to the US, as a representative of a western country. The 2009 study was conducted in India, Fiji, China, and the US did include drawings, but the final analysis focused more on participant interviews (Nastasia and Uppal 2010, 2014). The 2018 study which uses data collected in India and Fiji, replaces the US with Sweden, making the language variant a constant by only including countries that have languages other than English as their national language.

Participant-generated images: Considering the age range and culture differences in the sample, which can influence levels of articulation and methods of expression, participant-generated images (drawings) were included to allow expression without using language. Using this visual method is especially significant for working with young people because it empowers them by 'placing the agency literally in their own hands' (Literat 2013, p. 12) and increasing access to data without depending on language proficiency of the participants (Guillemin and Drew 2010). As an activity that is both 
playful and conducive to group activity, drawing is an efficient method that is ethically sound and can be applied across cultures (Literat 2013). In this particular study, drawings were used to transcend cultural differences and allow manifestation of local, culturally-appropriate images. A systematic analysis of drawings, can reveal a layered description of concepts, both emotional and cognitive, in a personally relevant manner (Literat 2013), which may be difficult to elicit if language were the only mode of communication.

\subsection{Intersecting Factors}

Considering the diversity of data, factors considered in analysis were identified before categorization and coding. The following factors were identified before data collection for comparing and contrasting: presence/absence of a royal family, geography, culture and dominant racial group in the country, language and presence of Disney and access to domestic and international media (Table 1).

Table 1. Variables considered in the study.

\begin{tabular}{|c|c|c|c|}
\hline & Sweden & India & Fiji \\
\hline Ethnicity and Culture & Mostly Caucasian & $\begin{array}{l}\text { Indian-Indians are a mix of } \\
\text { ethnicities and are not classified as } \\
\text { one single race. }\end{array}$ & $\begin{array}{c}\text { Fijian, Indo-Fijian, Other Pacific } \\
\text { Islanders, Chinese and other } \\
\text { minorities. }\end{array}$ \\
\hline Domestic Media & $\begin{array}{l}\text { Modest Domestic } \\
\text { Industry }\end{array}$ & $\begin{array}{l}\text { Robust domestic media industry, } \\
\text { but present media products are } \\
\text { highly influenced by western } \\
\text { media norms. By mid } 2000 \text { s, over } \\
80 \% \text { of children's programming } \\
\text { was imported }\end{array}$ & Minimal domestic media industry \\
\hline Transnational Media & $\begin{array}{l}\text { All media directed at } \\
\text { children is either in } \\
\text { Swedish or dubbed in } \\
\text { Swedish }\end{array}$ & $\begin{array}{l}\text { Media for children is available in a } \\
\text { variety of Indian languages, } \\
\text { including English. }\end{array}$ & $\begin{array}{l}\text { Most of the content for children is } \\
\text { imported and broadcasted in } \\
\text { English without any subtitles. } \\
\text { There is a small amount of local } \\
\text { programming for children in three } \\
\text { national languages English, Fijian } \\
\text { and Hindi. }\end{array}$ \\
\hline Form of Government & A democracy since 1917 & $\begin{array}{l}\text { A parliamentary democracy } \\
\text { since } 1947\end{array}$ & $\begin{array}{l}\text { Fiji has had four coups since } 1987 . \\
\text { Since its last election in } 2014 \text { was } \\
\text { deemed credible by international } \\
\text { media, it currently classifies itself } \\
\text { as a democracy. }\end{array}$ \\
\hline
\end{tabular}

Presence/Absence of Royal family: Royal families both in India and Fiji have been discontinued but Sweden maintains a Royal family which is regularly featured in the national media. Exposure to a real-life royal family in media was considered a factor of consequence in how girls between 8 and 15 perceived Disney princesses. Would the real-life experience allow for more realistic understanding of the princess concept?

Ethnicity, race, and culture: Geography was a significant consideration in this study. Ethnicity and race are autogenerated factors as a result of location of the three countries. Race, although not categorically defined in Fiji, India, and Sweden, all of which are multiethnic, varies in predominance.

Participants from Fiji had the least access to programming in their native language as compared to participants from India and Sweden. Sweden, although a multiethnic nation, is predominantly a Caucasian country, which makes it easy for the majority to identity with programming from western countries. In addition, since all the non-Swedish programming in Sweden is subtitled in Swedish, it provides a semblance of watching programming that is culturally similar. Although 'Indian' is not a race, it does present a different ethnicity from that of Fiji and Sweden, in addition to having access to domestic programming in several Indian languages featuring people of Indian descent. Disney has released several princess of color in the last 25 years. How does diversity in Disney's princess movies influence perception of princesses in countries that vary in production of domestic and culturally relevant programming? Do Disney's attempts at diversity empower girls to isolate their 
culture from global/transnational culture? Does that empowerment vary with ethnicity and race? Is the local/national culture reflected in the participant-generated images?

Language \& Presence of Disney: Access to Disney princesses in native language is another factor that can influence perception of Disney princesses. Fijian participants, who spoke both Fijian and English, could watch Disney only in English. Indian participants in this study were conversant in Hindi and English and had access to Disney princess movies in both languages. In Sweden, where all programming for children is dubbed in Swedish, participants had watched Disney princesses only in Swedish. Fiji was the only country in the study where Disney animated films were not dubbed into Fijian or Hindi, the two widely spoken languages in the country, other than English. Does watching Disney movies in one's own language make a difference in how being a girl is perceived?

Access to media/technology: Compared to Sweden, both in India and Fiji, access to technology is not uniformly distributed. To ensure access to transnational media, participants were limited to the middle class who had access to a home play-back system and cable. While the concept of middle class is relative, participants in India and Fiji were from families that had stable income, both parents were college-educated, and lived in capitals. While Disney's popularity is not restricted to any class, selecting a sample from the middle class ensured that the participants had consumed both Disney movies and products bearing the Disney brand. Data for Sweden, gathered in 2018, where rural-urban divide in media access is not as prominent, were gathered in Karlstad, a town of about 100,000 people, a three hour train-ride from the capital. The population in Sweden ${ }^{11}$ not only has near universal media access, but also more purchasing power for media technology, such as smartphones, laptops, tablets, etc.

\subsection{Research Questions}

The following secondary research questions were isolated from the overarching research question, which were then explored through data gathered for the study.

- RQ\#1: Considering Disney princesses are a global presence, how do the girls from countries that have had traditions of royalty (India and Fiji) in the past imagine princesses today? (drawings and interviews).

- RQ\#2: Does Disney's way of coloring and drawing the world of princesses (young girls drawn in primary colors, smiles, long dresses, and other accessories) influence young girls in their imagination and visualization of princesses? Does that vary in countries with different histories and cultures? (via drawings). Does that influence concepts of girlhood? (via interviews).

- RQ\#3: How do girls between 8 and 15 receive Disney princesses in a country that has a real-life royal family (Sweden)? (drawings) What roles do girls in a country with a real-life monarchy see princesses playing in real life, as compared to Disney princesses? (interviews).

- RQ\#4: Has young girls' way of visualizing princesses changed over time, since Disney has released several nonwestern princesses in the last decade?

- RQ\#5: How do girls (8-15) visualize princesses in the age of social media? Has the introduction of digital media influenced how the concept of a princess is consumed, understood, and applied?

\section{Sample and Data Collection}

The sample, in all the countries, was divided into three subgroups of 8-10,11-12, and 13-15, each with a minimum of five participants to allow for homogeneity of cognitive and expressive abilities in each group. In Fiji, where Fijians are the majority, the selected sample was restricted to girls of Fijian descent to allow a dataset least exposed to culturally relevant programming depicting characters with

11 Sweden, among the three countries has the least wage and wealth gap between professions. 
racial and cultural similarities. Girls of Fijian descent among all the three countries were also most exposed to transnational media, and characters who neither looked Fijian nor reflected Fijian culture.

Recruitment and Data Collection: Participants were recruited through personal contacts. Legal guardians of the participants were informed about the study through a written document. Those who volunteered to participate were invited to sign the consent forms. On the day of the study, participants and their guardians were invited to the research venue, offered light snacks, and encouraged to clear any doubts. Thereafter, participants were invited to a large meeting room, provided with pencils, plain sheets, and colors and asked to draw their version of a princess. No special instructions were given except, 'Draw what you think a princess looks like'. Only in Sweden, where the participants had reference to national princesses, were participants asked to give a name and age to the drawing, whereas in India and Fiji, the question was incorporated in focus groups. Since the participants were allowed to draw as many images they wished, the final number of drawings was greater than the number of participants, and the total number of drawings in each country was different. A total of 63 drawings, 16 from India, 26 from Fiji, and 21 from Sweden, were analyzed. One participant at a time was invited for an individual interview in a separate room to allow privacy, while the rest of the group continued drawing. Once all the individual interviews were complete, a focus group with all the participants was conducted. In all countries, the author was present at all the interviews. Research associates fluent in Fijian, Swedish, and Hindi were hired and were present at all the interviews. In addition to English, the author is fluent in Hindi and has intermediate fluency in Swedish.

In India and Fiji, where media access is not universal, the study began with a short viewing of clips of Mulan, Jasmine, and Pocahontas ${ }^{12}$, to ensure fresh memories of the Disney princesses with nonwestern heritage and the critical events they go through in the movies.

Interviews and focus groups: A standard set of questions was used in all the countries, with some added questions on access to technology and use of mobile media in Sweden. The age group 8-15 is impressionable, when both peers and media can have significance influence on self-perception (Blowers et al. 2003). Studying this age group can reveal how the princess concept is accepted, rejected, or critiqued by different age groups. Since 8-15 are crucial years when gender roles are learnt and a self-image is developing, it was important to ask questions about how the concept 'princess' was perceived by the participants. Individual interviews began with questions that could be broadly categorized into three: What do the participants understand by being a girl (Who is a princess? What does a princess grow up to be? Does a princess have friends?) How do girls perceive Disney princess (How does a princess appear, and behave with other people?) Does the girls' perception of princesses influence identifying with them? (What age did you start watching Disney princess films? Does a princess go to school? What kind of a school does a princess go to? How does she behave at school? Who is your favorite princess? Why/Why not? What do you like/dislike about a princess? Would you like to change anything about any of the Disney princesses? Would you like to be or have you ever wanted to be a princess? Do you think you could be a princess?').

Questions for focus group discussions were altered in the context of each country. In India and Fiji, where a movie clip-screening was held, participants were prompted to compare nonwestern princess, i.e., Mulan, Pocahontas, and Jasmine, to explore how nonwestern girls viewed Disney's representation of nonwestern princesses. In Sweden, where participants were not exposed to Disney movie clips, girls were asked if they knew of any nonwestern or ethnic Disney princess. Culture-specific follow-up questions were asked in each country, e.g., How do you compare real life princesses to Disney princesses (Sweden), Can you name a princesses from your country (India and Fiji). Since data from Sweden was gathered in 2018 in a different technological environment than 2009, an added

12 Moana, the first ever princess from the South Pacific was not released until 2016. 
emphasis was placed on the use of technology, viewing experience, reasons for preference of a platform such as computer, phone, TV, iPad etc. to access media during focus groups.

During the recordings, the primary researcher confirmed with the research associate to ensure that the correct follow-up questions were being asked. Both individual interviews and focus groups were recorded and transcribed. Transcriptions of interviews were tabulated after analyzing patterns, themes, and trends, within the context of geography, culture, and access to media. Images were subjected to a similar analysis, coding, and categorization which is explained in the following section.

\section{Coding and Categorization}

Drawings: To analyze sketches and gather images conjured up by the word 'princess', it was necessary to create categories that would compensate for differences in drawing abilities of the participants, while revealing meaningful patterns and themes that answered research questions, without requiring explanation from participants. Categories were created and the data were tabulated, after a systematic examination. Primary categories were: main colors used in the drawings-to examine what colors stand out prominent for the participants when conceiving a princess; outfit that the princess was wearing-categorized as long/medium/short dress that went down to the ankles, knees, or above the knees, respectively: to examine how a princess is depicted as formal, semiformal, or informal; the color of hair, black, brown, yellow (blonde), orange/red, or other. Artificial color such as green or blue, was put into the 'other' category; Facial expression-whether or not the princesses had a smile on her face, to investigate how happy a princess was perceived: coded with two values, yes/no; skin color, which was coded with four values, no color (wherever skin was left empty) and light (usually pink), yellow, brown/black, and other (tanned, orange, red, etc.): this was to assess if any race had been assigned to the princess. In the final analysis, light and no color were combined as portraying 'light skin'; crown/headdress/head-jewelry, evaluated by three values, yes or no and somewhat (clips, bows, decoration in hair). The category 'somewhat', a value given to head jewelry, received half the value of either crown or head-dress: to associate a certain position that made a princess stand out from civilians; and accessories: to study if any special accessories were presented with the drawing, e.g., wand, sash, extra jewelry, or similar objects. Finally, notes were taken about anything extra that was drawn. Since no specific instructions for drawing were given, each detail drawn also indicated an association with being a princess and assigning a status to the figure in the drawing. Two girls in Sweden drew cats, when asked to draw princesses, which, although included in the analyses, could not be judged on some aspects such as facial expression.

\section{Results and Analysis}

At this juncture, it is important to emphasize that the study is not implying a causal connection. However, since the study focuses on the concept of princesses, and specifically asked the participants about Disney princesses, the analysis thus concentrates on Disney's portrayals of princesses in particular, and examines how it is reflected in the drawings. Interviews and focus groups are used to further delve into the issue to explore any transference of, embodiment of, preference for values and characteristics represented by Disney princesses and explore new insights into the use of technology and access to Disney princesses.

Drawings: Despite the geographical diversity of the participants, and data that were collected nearly a decade apart, drawings from participants not only resembled Disney princesses, but also were more similar than different from each other (Figures 2-5). There was a noticeable commonality in drawings between data sets from 2009 and 2018, a period during which Disney released several movies with a princess of color with light skin (RQ\#2 \& RQ\#4). The consistent increase in the number of nonwhite princesses since Jasmine (Aladdin, 1992), however, has not replaced images of popular white princesses in Disney, that have a much older and global presence. The majority of participants from all countries drew princesses either with light skin or no skin color, leaving the skin as 'white', the color of the sheet provided during the study, with no noticeable difference between the data collected in 2009 
and 2018 (Table 2, Figures 2, 3 and 6 (2009), Figures 4 and 5 (2018)). Of all the participants, across all age groups in India and Fiji, two countries where light skin, akin to many Disney princesses such as Snow White or Cinderella, is rare, only two participants in India and none in Fiji, drew princesses with brown skin. In Sweden, where the majority of the population is Caucasian, even the mixed-race/nonwhite participants drew princesses with light skin color Figures 4, 5, 7 and 8 (2018). Participants in Fiji, a country with negligible domestic media content in Fijian, did not visualize princesses as people of color (Figures 2 and 9-12 (2009); Table 2; Figures 6 and 13), and some participants shared in interviews that they were too dark to be a princess themselves.

In Fiji, despite viewing movie clips of nonwestern princesses, six of the 11 girls in the 8-10 years group and three of ten in the 13-15 years group drew the Little Mermaid with long red hair, two participants in the 11-12 age group titled their drawing Sleeping beauty, and one in the same age group called hers a Cinderella, indicating the popularity of these movies (Figure 2) (RQ\#2). None of the participants in Fiji, where straight hair is rare among Fijian girls, drew princesses with curly hair (Figures 11 and 12). Instead, medium to long straight hair was common, three of 26 drawings had blonde hair and eight of the nine mermaids drawn had red hair, none of which are Fijian traits (Figures 9 and 10) (RQ\#2). One image in Fiji (Figure 11) had long blonde hair that almost covered the whole image. Similarly, Figure 3 from India and Figure 7 from Sweden show similarly prominent yellow hair. Although only one of 16 drawings of princesses from India had blonde hair, seven of 16 were drawn with auburn or brown hair, rather than black, the more common hair color in India (Figures 6 and 13) (RQ\#2).

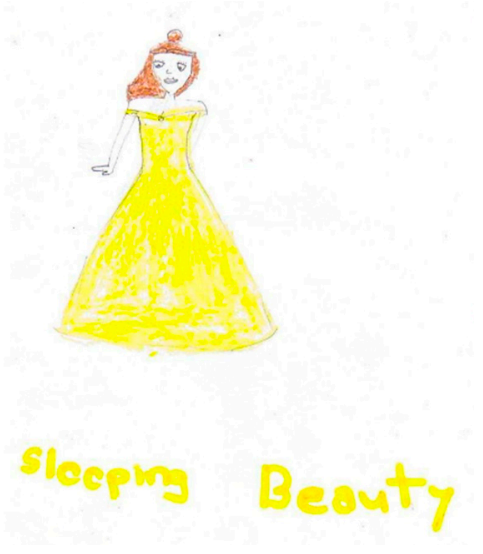

Figure 2. Fiji Sleeping Beauty 8-10.

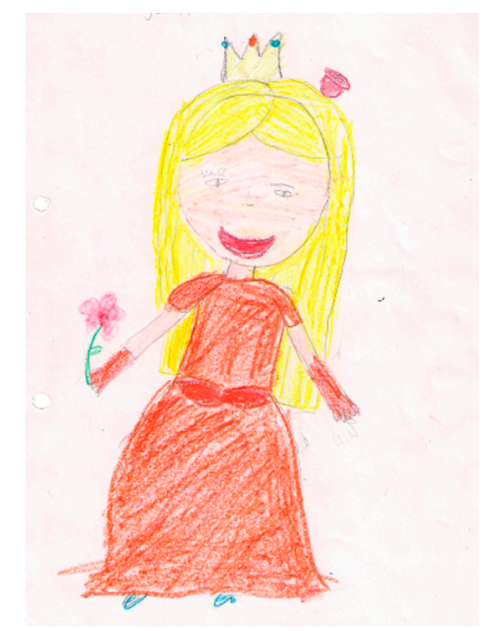

Figure 3. India Crown Blonde 8-10. 


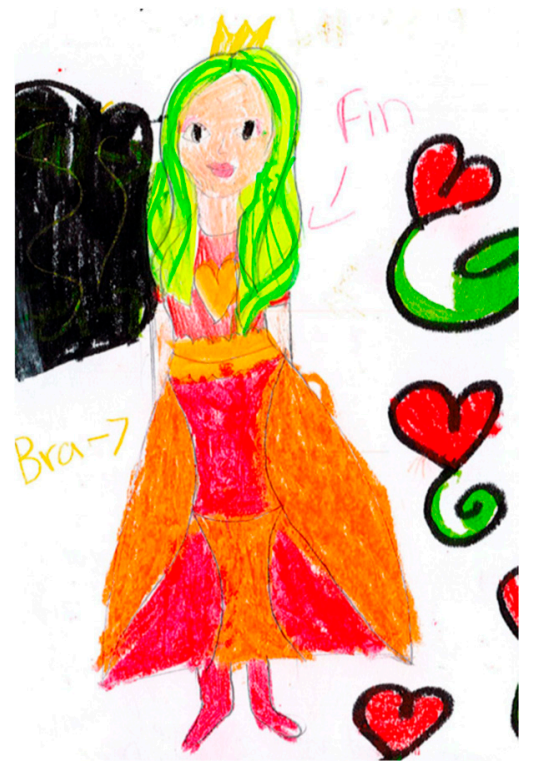

Figure 4. Sweden 8-10.

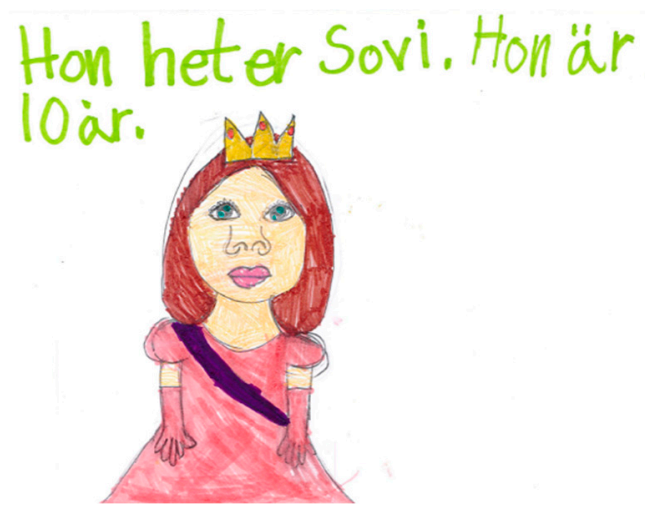

Figure 5. Sweden 8-10.

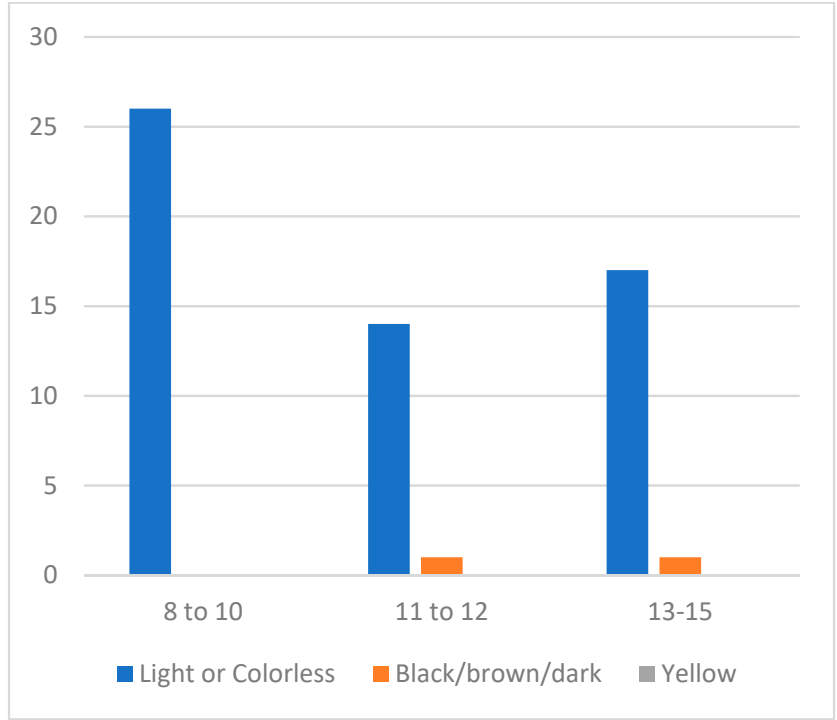

Figure 6. An overwhelmingly large number of girls across cultures drew princesses with light skin color. (The following table that was created after adding all data points from three countries, illustrates how across all age groups and in all countries, light colored princesses outnumbered tan or dark princesses.). 
Table 2. Despite the fact that between 2009 and 2018, several Disney princesses of color were released, participants in 2018 drew more princesses with light than dark skin color. Following table shows the percentage of light-colored princesses drawn across countries, age, and years.

\begin{tabular}{cccc}
\hline & $\begin{array}{c}\text { Year 2009 } \\
\text { Fiji }\end{array}$ & $\begin{array}{c}\text { Year 2009 } \\
\text { India }\end{array}$ & $\begin{array}{c}\text { Year 2018 } \\
\text { Sweden }\end{array}$ \\
\hline 8 to 10 & 100 & 67 & 83 \\
11 to 12 & 100 & 83 & 100 \\
13 to 15 & 100 & 83 & 88 \\
\hline
\end{tabular}

Notes: The percent of princesses that were drawn with light skin by country.

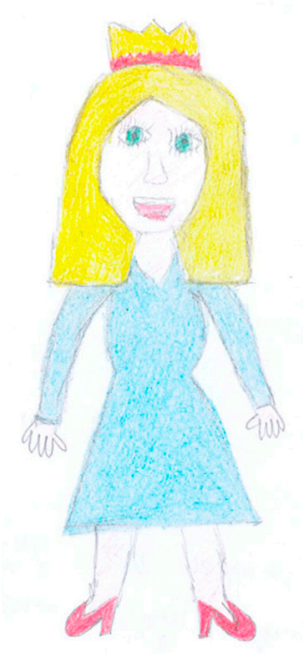

Figure 7. Sweden, Business wear \& Crown 13-15.

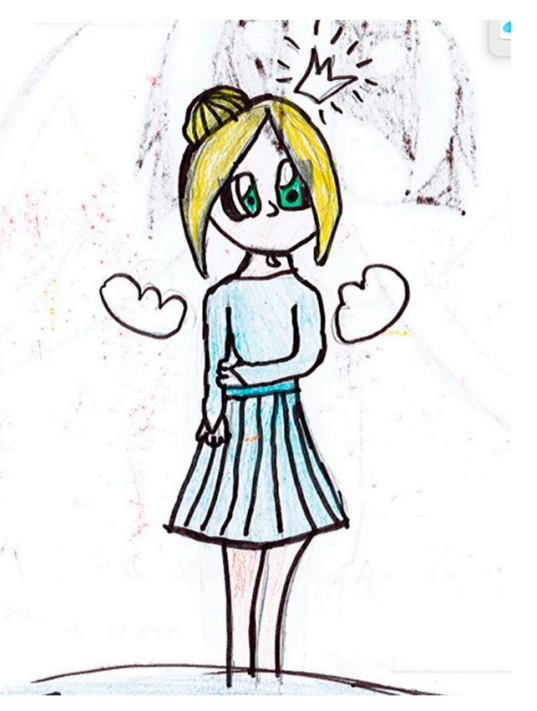

Figure 8. Sweden 8-10 Business Wear \& Crown.

Transnational media is critiqued for mainstreaming western beauty ideals, and aiding in deracinating young girls from their own culture. None of the participants in nonwestern countries, i.e., India and Fiji, drew princesses wearing traditional outfits, or with any cultural accessories such as anklets or nose ring for India and shell or flower jewelry in Fiji, that represented their respective national cultures (RQ\#1). Both in India and Fiji, not only were all the princesses drawn in western outfits or as 
mermaids, indicating a trend towards deracination and westernization, but also many drawings were made with long formal gowns, similar to the ones that Disney princesses wear (Figures 2, 9-11, 14 and 15) (RQ\#1\&2). No drawing in India, a country where wearing a saree is still an everyday affair, and many shows on TV portray princesses and queens in sarees, was drawn with a saree. No drawing from Fiji represented sulu-chamba, the traditional attire for Fijian women, indicating that the girls equated princesses with being western. In Sweden, where participants were exposed to real life princesses, about half of the total selected sample drew princesses in dresses categorized as 'medium dress' that were not formal gowns, but with a crown, indicating participants' experience with the princesses who follow a dress code for the length of dresses worn for business (Figures 7 and 8) (RQ\#2 \& RQ\#3). However, participants in Sweden also conceived of princesses as being much younger than the both of the current princesses in Sweden. When asked to give an age and a name for the princess drawn, only one participant (from the 11-12-year group) stated 30, whereas most participants placed princesses between 10 and 20 years of age. About half of the participants identified their princesses as a teenager, closer to how Disney princesses are presented. Even the 'cat princesses', drawn with a youthful look of flowers on their head (Figure 16) were given 'two animal' years, making them teenagers. At the time of this study, Swedish princesses, Princess Victoria and Princess Madeline, who are regularly featured in Swedish media were 41 and 36, respectively. None of the princesses were given the same name as either of the Swedish princesses, and none except one was given a name from a Disney princess, Belle (RQ \#3). Possibly taking a cue from the Swedish word 'Kronprincessa' crown princess-crowns featured more prominently in drawings by Swedish participants than in India and Fiji. Even though during the interviews several participants stated that the princesses usually feel restricted by the rules they have to follow, out of 63 drawings in total, forty were drawn with a clearly visible smile (Figures 3, $7,9,10$ and 14), indicating a sign of happiness and prosperity as Disney princesses are usually shown by the end of a movie. Distribution of the four categories of long gowns, smile, crown, and light skin, as shown in Figure 13, illustrates that girls in Fiji, who had least amount of access to media in Fijian, drew princesses far removed from their lived experience, mostly with light skin.

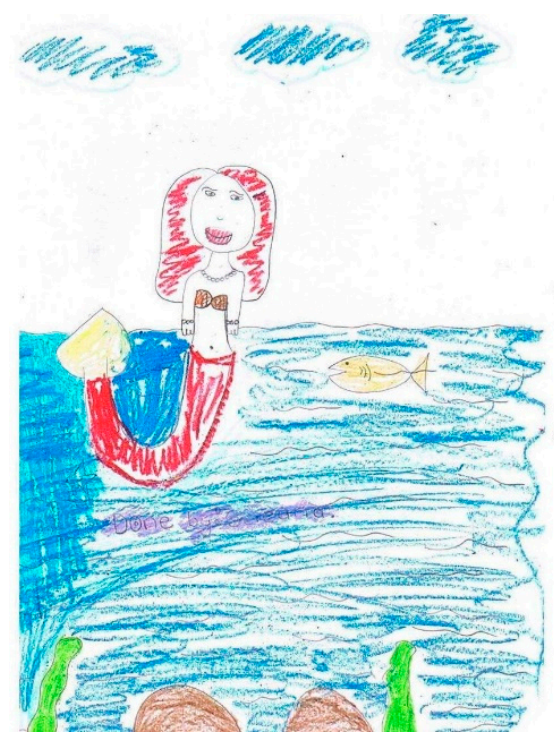

Figure 9. Fiji Mermaid 8-10. 


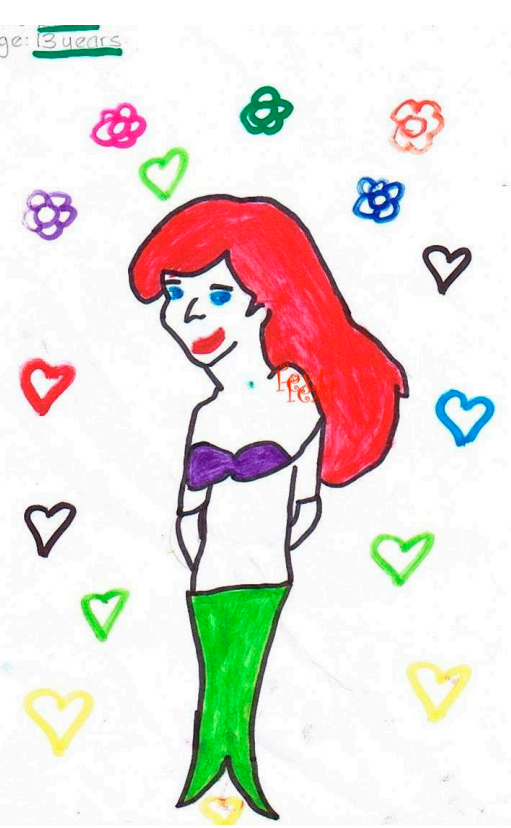

Figure 10. Fiji Mermaid 13-15.

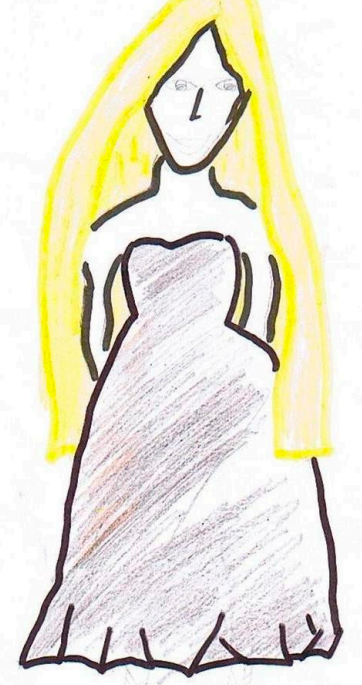

Figure 11. Fiji Long Hair 13-15. 


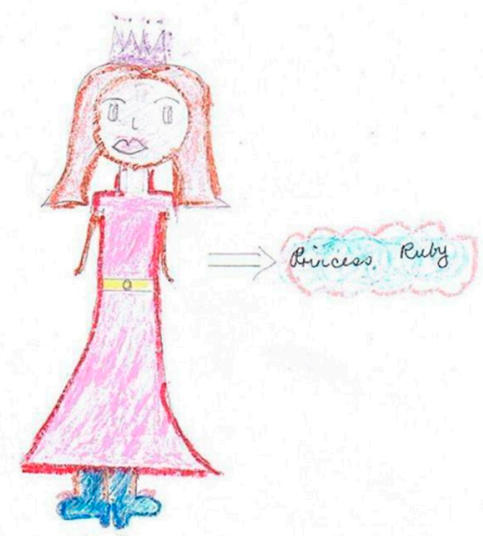

Figure 12. Fiji Straight Hair 11-12.

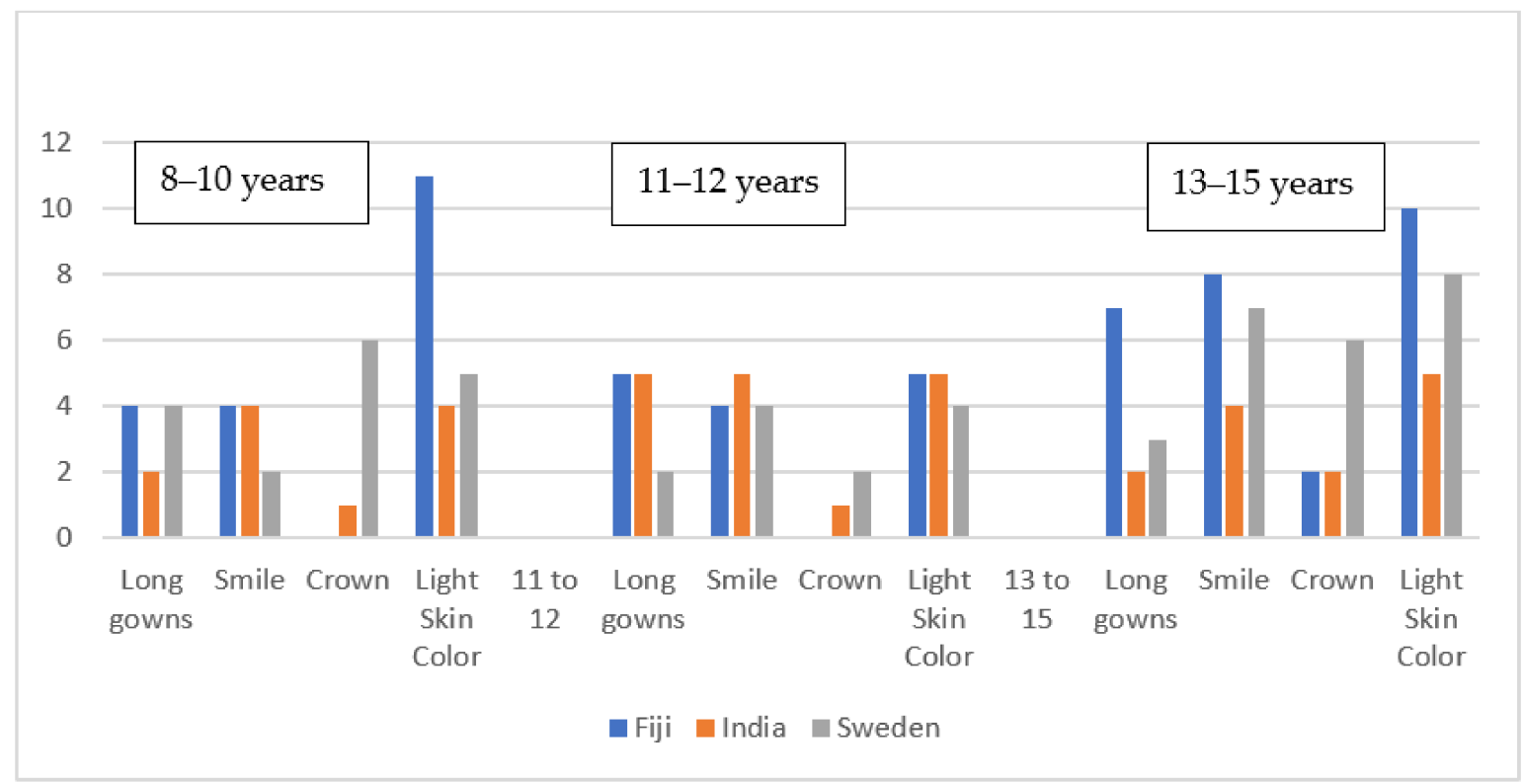

Figure 13. The distribution of four categories across drawings. (Long gowns, Smile, Crown, and Light Skin.).

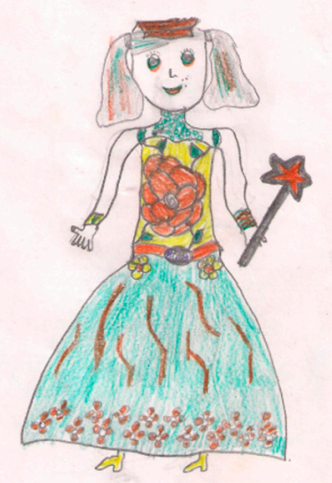

Figure 14. India, Gown \& Wand 13-15. 


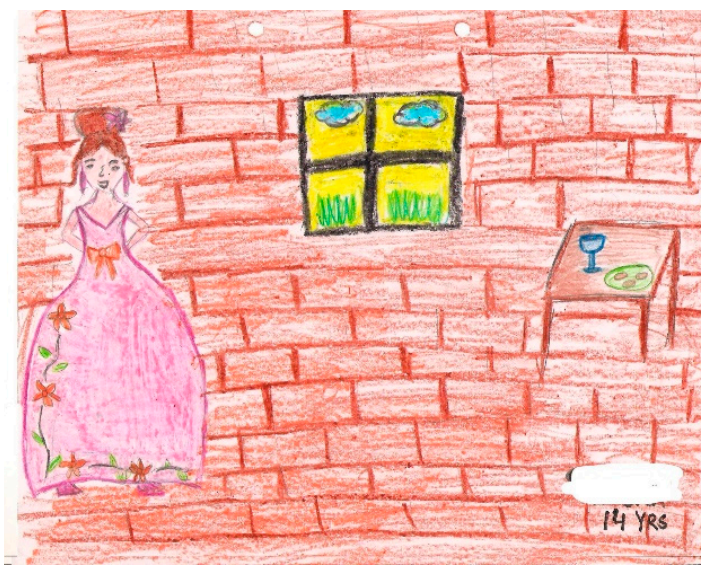

Figure 15. India, Gown 13-15.

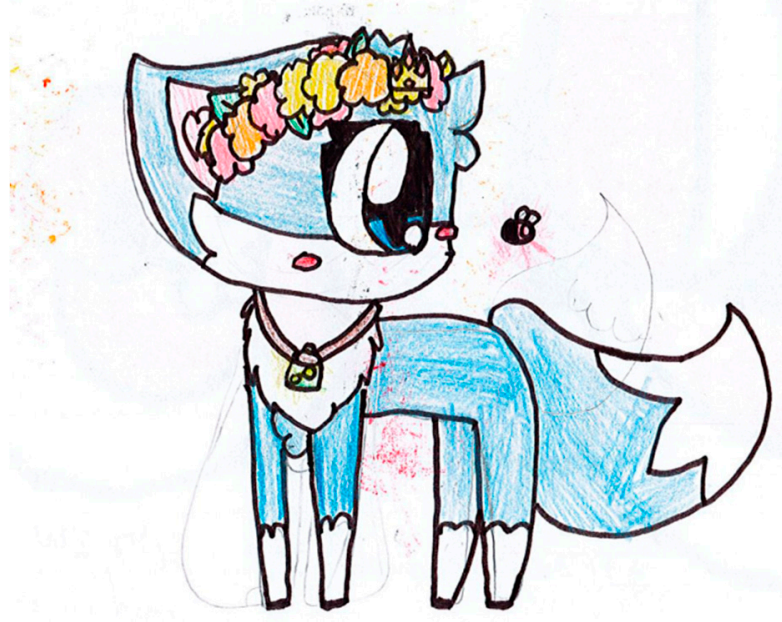

Figure 16. Sweden Cat Princesses 8-10.

Many participants in Fiji and India were not familiar with Aladdin, Mulan, and Pocahontas before the study, but almost all had seen classic Disney princess, namely Cinderella and Snow White, which explains why heels and wands were the most common accessories drawn in both the countries. The three main colors used across the countries were pink, red, and blue, followed by yellow and green (RQ\#2). Black, a color often used in Disney movies to depict evil, was used the least in dresses or accessories. No princess was drawn wearing trousers, even in India, where loose trousers are both casual and formal wear.

Interviews and focus groups: Participants in all three countries shared that Disney princess viewing had been a part of their childhood viewing from before they could remember. Both in India and Fiji, girls between 13 and 15 stated that they were slightly old for discussion on Disney princesses. In Sweden, girls of all age groups (2018) expressed that Disney princess movies were for girls in preschool, indicating an increase in availability of diversified age-specific media. Analysis of focus group and individual interviews identified popularity of Disney, and certain assumptions and trends, related to idea of princesses and being a girl, and media viewing, respectively.

Disney's popularity: Disney was equally popular in the three countries. Classic Disney princesses, such as Snow White, Cinderella, Sleeping Beauty, and the Little Mermaid, were more popular in all the three countries than Mulan, Pocahontas, or Jasmine. Snow White, Cinderella, and Sleeping Beauty were mentioned by participants of all age groups in the three countries. It is important to note that several girls in India and Fiji had not watched Mulan or Pocahontas. However, most participants were familiar with other princesses not mentioned in the briefing, e.g., Cinderella, Snow White, and 
Sleeping Beauty, which have been part of popular culture much longer and before the creation of Disney movies. Princesses of color, such as Mulan, Jasmine, and Pocahontas, were not as popular in any of the countries as Cinderella and Snow White (RQ\#1). Since 2009, Disney princesses have also been released as feature films, which participants of all age groups in Sweden preferred over animated versions ('I like to watch real people' (8-10, Sweden)).

Beauty, luxury, and youth: The most common feature in defining a princess in the three countries in all age groups was beauty and luxury. Princesses were defined as belonging to royalty, being the daughter of a King and a Queen, who lived in palaces, had expensive things, and wore fine and expensive dresses. Responses such as 'They will marry a prince' (13-15, India), 'They are waiting to be saved by a prince' (13-15, Sweden), 'They like boys, because they are always with a prince' (13-15, Fiji) indicated how girls in the 13-15 age group in all countries considered a prince and marriage being significant to princess's identity. A reflection of age (13-15) when the participants interest in the opposite sex is increasing, the need for a prince was expressed differently in each country. In India, the focus was on marriage, in Sweden on princesses' helplessness in Disney movies, and in Fiji, the focus was on socialization. This difference also reflects cultural differences; for example, Sweden's commitment to gender equality encourages girls to be self-reliant, weddings and marital status are significant in India, where many Bollywood movies use wedding as a plot, and in Fiji culture, social standing is significant in everyday socialization. This, however, does not imply that no girls in Sweden wish for a marriage/long term commitment, or that girls in India and Fiji are not encouraged to be self-reliant.

Consistent with drawings, girls in all countries associated princesses to be young girls, no more than 21 years of age, with the exception of one participant in Sweden who listed a princess age of 30.

Being a girl: When asked which princess they thought represented their country, most participants in India and Fiji did not have a response, although some pointed at Jasmine being relatable. Girls in Sweden (8-11) said that Elsa from Frozen seemed like a Nordic princess because she was surrounded by snow and fjords. Responses to question about learning from a Disney princess varied by age, despite several common factors. Age groups 8-10 and 11-12 in all countries stated they could learn to be kind, polite, and brave. However, both in India and Fiji, girls added qualities of learning how to dress up and look nice. A participant in Fiji stated (after viewing Disney princesses) 'now I ask my parents to buy me more dresses' (8-10 year, Fiji). Both 11-12 and 13-15 age groups in all the countries were critical of princesses and stated that they were not real people, 'only cartoons, only stories'. Both the age groups in all the countries also recognized that princesses had little freedom, and their lives seemed boring. When asked if princesses go to school, some girls in India and Fiji stated that 'princess do not need to learn anything because they would have servants for everything'. Indicating a low media profile kept by the Swedish Royal family, participants in Sweden in all age groups stated that they were not sure which school princesses attended but 'they are likely to attend a 'private or special schools or even be homeschooled' (11-12 Sweden).

Most participants across age groups and in all three countries denied wanting to be a princess, but reasons were different across age groups and between the countries. Some reasons, reflected even in drawings, seemed to coincide with images perpetuated by Disney movies, such as princesses being beautiful and light skinned. Standardization of beauty in Disney princess movies was reflected in responses and drawings from all countries. As many participants stated, 'princesses are beautiful, wear long dresses and have long hair'. Lived experience of participants was reflected in some of the responses. For example, girls in Sweden mentioned being 'blonde', as one of the qualities, more so than in India and Fiji. However, since beauty and wealth in nonwestern countries that were colonized is usually associated with being light-skinned (Ralson 1997; Glenn 2008), participants in India and Fiji, both colonized by the British, stated 'fair skin and long straight hair' as being princess traits. The most common responses in Fiji were 'I do not belong to a royal family, am not light skinned, and not as polite, so cannot be a princess.' (across all age groups in Fiji) Girls in both nonwestern countries emphasized skin color more than those in Sweden as a prerequisite for being beautiful (and how a princess was 
envisioned). In addition, girls in Fiji always had someone they knew was prettier than they, and more likely to be a princess, because she was 'slim, tall or long haired'. Disney's representation of princesses reinforces the same beauty ideals of the west and caucasianizes their lead characters in features, body traits, and mannerisms, even when they are not Caucasian. A participant in Fiji (11-12) stated 'Pocahontas is palangi (white), because of the way she talks'. Another participant in India (8-10) said that 'only Jasmine was Indian' among the three princesses they watched in the movie clips and 'Mulan and Pocahontas were American'.

In comparison, participants in Sweden, stated not wanting to be a princess because their lives would be boring. The concept of a royal's life being 'boring' may result from seeing real princesses' in official gatherings where they perform a merely ceremonial function, i.e., cutting a ribbon, shaking hands, etc. In many televised events, such as the Nobel Prize Ceremony, the royal family has a minimal role to play. However, one participant in Sweden (11-12) lamented that 'it was not fair that the media gets to talk about princesses' birthdays, while ordinary girls never have their birthdays celebrated on television.'

Girls in all countries, especially between the ages of 11 and 15, stated lack of freedom as one of the reasons for not wanting to be a princess; however, there was a sense of agency in participants from Sweden. The word 'beauty' was used more often in India and Fiji than in Sweden. Although characteristics identified for princesses were the same in all the three countries, e.g., long hair, dresses, and expensive jewelry, girls in Sweden did not label those characteristics as being 'beautiful'. Being Caucasian removed the pressure to be someone else in order to be labelled attractive, which is a colonial residue for many post-colonial states, where beauty is equated with having light skin.

Language and Culture: In countries with colonial history, the language of colonizers is associated with being sophisticated and well-educated. Participants in India preferred to speak in English during the interview.

Participants in India and Fiji, who watched movies in English, did not see much difference between Jasmine, Pocahontas, and Mulan, all of whom looked 'American'. 'Because they look, behave and talk like an American', was a common explanation, but they were considered different from 'Snow White, and Cinderella' because of their skin color.

Consistent with findings of an earlier study (Nastasia and Uppal 2014; Nastasia and Uppal 2010), girls in both the nonwestern countries, who watched movies in English considered all the nonwestern princesses as American, indicating that young girls did not recognize any Indian or Fijian or nonwestern traits in princesses of color. The earlier study that included participants from three nonwestern countries-India, China, and Fiji-and the US, established that princesses were considered synonymous with beauty in all four countries and across all age groups (Nastasia and Uppal 2010, 2014). However, participants from all three nonwestern countries considered Mulan and Pocahontas as American and not Chinese or Native American. Participants from the US, who were divided into four racial groups to explore how race and nationality influence participants' perception of Disney princesses $^{13}$, were 'color blind' and identified with Jasmine, Pocahontas, and Mulan regardless of race (Nastasia and Uppal 2010, 2014). This identification may be attributed to the participants being American and identifying with language, accent, and mannerisms, the same attributes that distanced girls in China, India, and Fiji from princesses of color, indicating that Disney princesses, regardless of their ethnicity, are perceived to be western and American. Girls both in India and Fiji stated that princesses of color such as Jasmine or Mulan were actually American. 'Jasmine's skin is like an American, but hair and face is like an Indian', said a Fijian participant (8-10) who watched the movie in English, and indicated that 'Jasmine behaved like an American'. A participant from India (8-10) stated that 'only Jasmine was Indian, but others (Mulan and Pocahontas) were American. In comparison,

13 Participants in the US were chosen to represent Caucasian Americans, Native Americans, African Americans, and Chinese Americans. 
girls in Sweden who watched the movies in Swedish considered Jasmine to be from Egypt and could pronounce 'Aladdin' appropriately, rather than with American pronunciation, as it is in the English version. The language in which movies are viewed seems to have had an influence, because viewing movies in English, for girls whose first language was not English, made the girls feel the characters were American and distant from them. Disney movies have been critiqued for using accents inconsistently and inappropriately, e.g., several negative characters have non-American accents, and orthodox or old-fashioned characters such as the Sultan in Aladdin are depicted with a non-American accent, even though his daughter, the lead in the movie, talks with an American accent. Such creative liberties use accents to label characters as progressive, evil, or orthodox, can be confusing for young viewers.

When asked to name princesses from their culture, girls from Fiji and India either had no response or took a long time to come up with historical names like 'Jhansi Ki Raani' (India). Girls in India, where stories of several princesses have been made into TV series, did not consider Disney princesses and 'Indian' princess in the same category, because 'Indian princesses are always related to war, Disney princesses have their personal issues' (13-15, India) (RQ \#1). One girl in Fiji named 'Princess Ruby' that she said she had read about in a book.

Responsibilities and Rights: Participants in all the countries articulated that princesses, despite being rich and leading a luxurious life, had responsibilities towards their 'people'. Girls in all countries emphasized kindness and responsibilities of a princess, but those in Sweden emphasized 'real work', e.g., attending meetings, representing the country to other countries, taking care of animals, etc. (RQ\# 3). Understanding of princesses and their responsibilities both in India and Fiji were consistent with Disney's portrayal. However, participants in Sweden derived their understanding from coverage of the Swedish Royal family.

New media, New interaction, New princesses: Data from Statistics Sweden (2018) indicated new trends and directions in media viewing and media consumption. Participants in all age groups stated being too old for Disney movies; however, they shared their interest in the Disney princesses in feature films such as the recent Cinderella and Beauty and the Beast. 'They look like real people'. However, girls in the age group of 11-15 mentioned following several YouTubers, such as Terese Lindgren, who is also 'blonde, has many things, loves animals, and has nice things'. (RQ \#5). When asked in the focus group, 'but don't you think that they have the same qualities you mentioned in Disney princesses?', the girls (13-15), responded, 'maybe, have not thought about it', but they considered the YouTubers to be 'real people' An earlier study (Lövheim 2011) has established popularity of young girl bloggers in Sweden, where bloggers conduct themselves with a certain distance and provide limited access to their blogs, much like royalty or celebrities, resulting in their popularity. Other shows mentioned by girls in Sweden, such as High School Musical and Soy Luna are also Disney productions and perpetuate the same concepts of being a girl, such as being beautiful and independent (RQ\#5). Despite the change in media viewing, from TV and DVD playback in Fiji and India at the time of data collection (2009) to mobile media, such as iPads, Laptops, and smartphones, as the primary viewing platform in Statistics Sweden (2018) the concept of beauty and how a princess looks has not altered with time (RQ\#5).

All age groups in Sweden indicated having access to mobile media and the internet. Girls in the 13-15 age group in Sweden stated that they had owned smart phones for four to six years and accessed media mostly on their phones. Multitasking, viewing several programs simultaneously while using snapchat was common among 13-15-year-olds. Most girls had access to Netflix on their phones and there was no restriction on screen time by their parents, but some participants indicated that they had school and house work-related chores that they needed to complete, which limited their screen time, indicating the role parents can play in regulating media usage.

\section{Conclusions}

Even though a causal connection between watching Disney and a specific way of viewing and organizing the world for its young viewers is not indicated, the ubiquity of and replication of images 
produced by Disney products clearly matters. In various media and materials in daily lives, e.g., movie characters, school supplies, outfits, wall hangings, bed-linen, toys, etc. and the drawings made by the participants, may provide alternative images of girlhood in many countries, especially in those with a paucity of domestic programming. What features constituted beauty, the visualization of princesses and factors seen as integral to being a girl were consistent between 2009 and 2018. Most prominently indicated as representing beauty were youth and light skin color. Being white and young was considered to be the norm of beauty, especially for nonwhite, nonwestern participants. Whiteness intertwined with girlhood in both Disney and other media and its use (by media) gets reinforced in the public with repetitive use, e.g., Projansky (2014) cites the use of a single image of a blonde girl to evoke sympathy about the Connecticut shooting in 2012, while both girls and boys, white and nonwhite children were affected by the incident. Even though it impacts both whites and nonwhites, whiteness, as perpetuated by media, becomes the face of an event/tragedy, making alternative faces/races invisible in the media, and therefore less likely to be recognized and able to evoke empathy. In 2014, Disney released the song 'Let it Go' from Frozen in 25 languages, and was critiqued for the fact that none of the Indian or African languages were included in the release. ${ }^{14}$ Disney's portrayal of princesses, even princesses of color, seems be through a western lens, which does not allow girls of color to identify with the characters. Instead, girls in Fiji and India, despite having watched clips of Mulan, Jasmine, and Pocahontas, indicated that they did not possess the right qualities for being a princess, especially skin color, nor did they identify with any of the princesses, nor could they correctly place the countries to which the princesses belonged. Disney's depiction of princesses only provides surface diversity, which upholds norms of western beauty (light skin, long-straight-blonde hair) and western values (independence and self-reliance at the expense of personal relationships) (Limbach 2013; Garabedian 2015).

Presence of domestic media provided some alternative images from the home culture, e.g., participants in India who had access to images of young women who looked like them more than the participants in Fiji, drew more nonwhite princesses. Girls in Fiji, who were exposed to the most nondomestic media, expressed their inadequacy at being a princess the most. Beyond the language in which Disney movies are viewed, participants both in India and Fiji stated that they did not identify with Disney princesses. However, a significant impact of Disney movies was reflected in association of royalty/princesses with western outfits, as none of the participants from India and Fiji drew princesses in traditional Indian or Fijian outfits. Significance of culturally similar images and use of native languages in media products in building a positive self-image was reflected in responses and drawings by participants in Sweden who did not associate having light skin with being beautiful, modern or stylish as did girls in India and Fiji.

Disney's impact is not restricted to Disney animated princesses, because the company also creates celebrities who are presented as princesses for young girls to emulate, through shows such as Hanna Montana (Projansky 2014). The characteristics once identified with princesses are embodied by new, young, and technologically hip personalities on social media. These 'princess-like characters' who are 'kind, nice to animals, and want to share the things they have' are the new bloggers and YouTubers who personify the princess characteristics and become role models for young girls. The ideas of beauty and being a girl, perpetuated by Disney animated princesses, are now demonstrated by many vloggers, who are the new princesses sitting in their home studios talking directly to young girls on their personal phones. Disney has, over the last century, standardized beauty ideals, which are copied even by domestic media industries, as is evident in Indian media industry.

Today, media have an intimate presence in the lives of the young. As media scholars and critics continue to highlight the combined impact of the lack of domestic media in many nations, the ubiquity

14 https://www.pri.org/stories/2014-01-24/no-room-african-or-indian-languages-disney-s-multilingual-version-let-it-go. PRI reporter Patrick Cox. 24 January 2014·6:30 p.m. EST. (accessed on 14 October 2018). 
of the western English-speaking media and the narrow understanding of being a girl perpetuated by Disney princesses become more evident. The role of educators, parents, and caretakers must be considered in providing alternative activities that allow for realistic and culture-specific portrayals in empowering young girls.

Funding: The first part of this study conducted in 2009 was funded by Internationales Zentralinstitut Fur Das (IZI) Jugend-Und Bildungsfernserhen, Munchen, Germany.

Acknowledgments: The author would like to thank all those who assisted in research, transcription and interpretation for this project. Thanks are due to Ratan Chauddhary (India), Renuka Prasad and Ana Kitolelei (Fiji), and Jenny Jansdotter and Charlotta Fox (Sweden) for assistance with interpretation and transcription. I would also like to thank Diana Nastasia who was a collaborator on the 2009 part of the study and vital to the development, design and implementation of the study.

Conflicts of Interest: The author declares no conflict of interest.

\section{References}

Åse, Cecilia. 2013. Monarchical Manoeuvres: Gender, Nation and the Boundary Problem in Post-War Swedish Constitutional Development. NORA—Nordic Journal of Feminist and Gender Research 21: 172-86. [CrossRef]

Balmer, John M. T. 2011. Corporate Heritage Identities, Corporate Heritage Brands and the Multiple Heritage Identities of the British Monarchy. European Journal of Marketing 45: 1380-98. [CrossRef]

Blowers, Lucy C., Natalie J. Loxton, Megan Grady-Flesser, Stefano Occhipinti, and Sharon Dawe. 2003. The Relationship between Sociocultural Pressure to Be Thin and Body Dissatisfaction in Preadolescent Girls. Eating Behaviors 4: 229-44. [CrossRef]

Clarke, Alison. 2007. Coming of Age in Suburbia: Gifting the Consumer Child. In Designing Modern Childhoods: History, Space and the Material Culture of Child. Edited by Maria Gutman and Ning De Coninck-Smith. The Rutgers Series in Childhood Studies; New Jersey: Rutgers University Press, pp. 253-68.

Dorfman, Ariel, and Armand Mattelart. 1975. How to Read Donald Duck. New York: International General.

Dundes, Lauren, and Madeline Streiff. 2016. Reel Royal Diversity? The Glass Ceiling in Disney's Mulan and Princess and the Frog. Societies 6: 35. [CrossRef]

England, Dawn Elizabeth, Lara Descartes, and Melissa A. Collier-Meek. 2011. Gender Role Portrayal and the Disney Princesses. Sex Roles 64: 555-67. [CrossRef]

Forman-Brunell, Miriam, and Rebecca C. Hains, eds. 2014. Princess Cultures: Mediating Girls, Imaginations and Identities. (Mediated Youth). New York: Peter Lang, vol. 18.

Garabedian, Juliana. 2015. Animating Gender Roles: How Disney Is Redefining the Modern Princess. James Madison Undergraduate Research Journal 2: 22-25.

Glenn, Evelyn Nakano. 2008. Yearning for Lightness: Transnational Circuits in the Marketing and Consumption of Skin Lighteners. Gender \& Society 22: 281-302. [CrossRef]

Golden, Julia C., and Jennifer Wallace Jacoby. 2018. Playing Princess: Preschool Girls' Interpretations of Gender Stereotypes in Disney Princess Media. Sex Roles 79: 299-313. [CrossRef]

Götz, Maya, and Dafna Lemish, eds. 2012. Sexy Girls, Heroes and Funny Losers: Gender Representations in Children's TV around the World. Frankfurt am Main. New York: Peter Lang.

Guillemin, Marilyn, and Sarah Drew. 2010. Questions of Process in Participant-Generated Visual Methodologies. Visual Studies 25: 175-88. [CrossRef]

Hains, Rebecca C. 2007. Inventing the Teenage Girl: The Construction of Female Identity in Nickelodeon's My Life as a Teenage Robot. Popular Communication 5: 191-213. [CrossRef]

International Data on Youth and Media. 2017. BR Current Surveys and Research Compiled by Heike vom Orde (IZI) and Dr. Alexandra Durner. Available online: http://www.br-online.de/jugend/izi/english/International\% 20Data\%20on\%20Youth\%20and\%20Media.pdf (accessed on 30 September 2018).

James, Allison, Chris Jenks, and Alan Prout. 1998. Theorizing Childhood. Repr. Cambridge: Polity Press.

Jiang, Jingjing. 2018. How Teens and Parents Navigate Screen Time and Device Distract. Washington: Pew Research Center, Available online: http://www.pewinternet.org/2018/08/22/how-teens-and-parents-navigate-screentime-and-device-distractions/ (accessed on 20 September 2018).

Jönsson, Mats, and Patrik Lundell, eds. 2009. Media and Monarchy in Sweden. Göteborg: Nordicom. 
Lawrence, Elizabeth A. 1986. In the Mick of Time Reflections on Disney's Ageless Mouse. The Journal of Popular Culture 20: 65-72. [CrossRef]

Lemish, Dafna. 2010. Screening Gender on Children's Television: The Views of Producers around the World, 1st ed. London and New York: Routledge.

Limbach, Gwendolyn. 2013. You the Man, Well, Sorta: Gender Binaries and Liminality in Mulan. In Diversity in Disney Films: Critical Essays on Race, Ethnicity, Gender, Sexuality and Disability. Edited by Johnson Cheu. Jefferson: McFarland \& Company, pp. 115-28.

Literat, Ioana. 2013. 'A Pencil for Your Thoughts': Participatory Drawing as a Visual Research Method with Children and Youth. International Journal of Qualitative Methods 12: 84-98. [CrossRef]

Lövheim, Mia. 2011. Young Women's Blogs AS ETHICAL SPACES. Information, Communication E Society 14: 338-54. [CrossRef]

Nastasia, Diana, and Charu Uppal. 2010. Learning About Being a Girl, From Disney Princesses. Munich: TELEVIZION, pp. 34-37.

Nastasia, Diana, and Charu Uppal. 2014. Mono- or Multi-Culturalism: Girls Around the World Interpret Disney Princesses with Nonwestern Heritage. In Princess Cultures: Mediating Girls' Imaginations and Identities. Edited by M Forman-Brunell and Rebecca C. Hains. New York: Peter Lang, pp. 115-38.

Otnes, Cele, and Pauline Maclaran. 2015. Royal Fever: The British Monarchy in Consumer Culture. Oakland: University of California.

Pollen, Annebella. 2011. Performing Spectacular Girlhood: Mass-Produced Dressing-Up Costumes and the Commodification of Imagination. Textile History 42: 162-80. [CrossRef]

Projansky, Sarah. 2014. Spectacular Girls: Media Fascination and Celebrity Culture. New York: New York University Press.

Ralson, Helen. 1997. Arranged, 'semi-Arranged and 'Love' Marriages among South Asian Immigrant Women in the Diaspora and Their Non-Immigrant Sisters in India and Fiji: A Comparative Study. International Journal of Sociology of the Family 27: 43-68.

Rehmann, Bettina. 2010. The Swedish Media System. München: GRIN Verlag, Available online: http://nbn-resolving. de/urn:nbn:de:101:1-2010091613271 (accessed on 21 September 2018).

Schickel, Richard. 1997. The Disney Version: The Life, Times, Art, and Commerce of Walt Disney, 3rd ed. Chicago: Ivan R. Dee.

Statistics Sweden. 2018. Access to the Internet by Type of Device, Sex and Study Domain. Available online: https://www.scb.se/en/ (accessed on 31 March 2019).

Stehn, Molly. 2018. A Brilliant but Frosty Solution: Frozen ${ }^{\circledR}$ as an Allegory for the Central Relational Paradox. Journal of Creativity in Mental Health 13: 254-61. [CrossRef]

Turkle, Sherry. 2011. Alone Together: Why We Expect More from Technology and Less from Each Other. New York: Basic Books.

Verma, Suman, and Deepali Sharma. 2003. Cultural Continuity Amid Social Change: Adolescents' Use of Free Time in India. New Directions for Child and Adolescent Development 2003: 37-52. [CrossRef] [PubMed]

Wasko, Janet. 2001. Understanding Disney: The Manufacture of Fantasy. Cambridge: Polity, Malden: Blackwell.

Widestedt, Kristina. 2009. Pressing the Centre of Attention: Three Royal Weddings and a Media Myth. In Media and Monarchy in Sweden. Edited by Mats Jönsson and Patrik Lundell. Göteborg: Nordicom.

Wohlwend, Karen E. 2009. Damsels in Discourse: Girls Consuming and Producing Identity Texts Through Disney Princess Play. Reading Research Quarterly 44: 57-83. [CrossRef]

(C) 2019 by the author. Licensee MDPI, Basel, Switzerland. This article is an open access article distributed under the terms and conditions of the Creative Commons Attribution (CC BY) license (http://creativecommons.org/licenses/by/4.0/). 